\title{
Plasma Mannoheptulose Kinetics in Adult Domestic Short-Haired Felines
}

\author{
Anna K Shoveller ${ }^{1 *}$, Leslie L McKnight ${ }^{1}$ and Gary M Davenport ${ }^{2}$ \\ ${ }^{1}$ Centre for Nutrition Modeling, Department of Animal Biosciences, University of Guelph, Canada \\ ${ }^{2}$ The lams Company, Research and Development, USA
}

\begin{abstract}
Mannoheptulose $(\mathrm{MH})$, a sugar found in avocados that inhibits glycolysis, has been investigated as a functional feed ingredient for canines. However, no studies have sought to feed $\mathrm{MH}$ to felines. The purpose of this study was to assess whether ingested $\mathrm{MH}$ appears in peripheral circulation of adult domestic short-hair felines $(\mathrm{N}=10,4.1 \pm 0.1 \mathrm{~kg}, 1.6 \mathrm{y})$ fed a $\mathrm{MH}$ containing diet. The study was designed as a randomized cross-over with each cat receiving dietary treatments, control and $\mathrm{MH}$. Each study period lasted 28 $\mathrm{d}$ and a meal challenge was performed on $\mathrm{d} 28$. Felines were fasted overnight, anaesthetized, and a catheter was inserted into the jugular vein for repeated blood sampling. A fasting blood sample was collected six hours after catheter placement. Subsequently, felines were offered their full daily ration of test diet and blood was collected every $2 \mathrm{~h}$ during the $24 \mathrm{~h}$ post-prandial period for analysis of plasma $\mathrm{MH}$. Ingested $\mathrm{MH}$ appeared in the plasma within $2 \mathrm{~h}$ of ingestion confirming that dietary $\mathrm{MH}$ is absorbed and available for cellular uptake. Circulating $\mathrm{MH}$ was cleared from plasma within $24 \mathrm{~h}$ of ingestion. The differences in plasma $\mathrm{MH}$ kinetics between species are likely attributed to differences in feline carbohydrate metabolism relative to other mammals. No $\mathrm{MH}$ was detected in cats fed the control diet. These results suggest that $\mathrm{MH}$ is digested, absorbed and available from peripheral circulation in adult cats. Finally, MH remains in circulation longer than in dogs and may suggest that cats would only need a lower dose or fewer doses of $\mathrm{MH}$ per day.
\end{abstract}

Keywords: Mannoheptulose; Diet; Glucose

\section{Introduction}

In both humans and companion animals there is a growing interest in the use of plant derived dietary supplements and functional feed ingredients ("nutraceuticals") to promote healthy weight maintenance. Mannoheptulose $(\mathrm{MH})$, a sugar found in high concentrations in avocados, has been preliminarily evaluated as a functional food ingredient for dogs [1-4]. The metabolic effects of $\mathrm{MH}$ are due to its ability to competitively inhibit hexokinases $[5,6]$. The potential for $\mathrm{MH}$ to limit glucose availability via glycolytic inhibition may consequently lead to increases in fat utilization. With prolonged daily feeding, increased fat utilization may lead to changes in body composition. Being obligate carnivores cats have several idiosyncracies in carbohydrate metabolism. For example, cats have notably lower hepatic glucokinase (hexokinase IV) activity [7] in comparison to omnivores. The potential for $\mathrm{MH}$ to further suppress hexokinase activities and proceeding metabolic consequences are unknown as no one has sought to feed $\mathrm{MH}$ to cats. These hypotheses remain to be tested, but make $\mathrm{MH}$ an appealing target for further investigation, especially in companion animals where the incidence of obesity and associated metabolic disorders is increasing. The purpose of this study was to determine the availability of ingested $\mathrm{MH}$ in adult cats. Specifically, we aimed to describe the appearance and disappearance circulating $\mathrm{MH}$ in cats fed a $\mathrm{MH}$ containing meal.

\section{Methods and Materials}

\section{Animals and housing}

All procedures were approved by the Institutional Animal Care and Use Committee of The Iams Company (Lewisburg, OH). Ten domestic shorthair felines ( 5 neutered males and 5 spayed females, 4.08 $\pm 0.06 \mathrm{~kg}, 1.6 \mathrm{y})$ were used in this study. All cats were deemed healthy at the initiation of the study based on a standard physical examination conducted by an accredited veterinarian. All animals resided at the The Iams Company Pet Health and Nutrition Center (The Iams Company, Lewisburg, OH). Cats were group housed with free access to water and indoor and outdoor housing areas. Indoor and outdoor areas were equipped with beds, toys, climbers and scratching posts for environmental enrichment.

\section{Study design}

This study was designed as a cross-over with each cat receiving both dietary treatments, control $(\mathrm{CON})$ and mannoheptulose $(\mathrm{MH})$, in random order. Seven days prior to study initiation (wash in) and for seven days between study periods (wash out) all cats received the CON diet. After the 7 day washout periods, cats were placed on one of two dietary treatments and fed treatment diets for 28 days. On the final day of the experimental period ( $\mathrm{d} 28$ ) a meal challenge was performed (Table 1).

\section{Diets and feeding}

Test diets were formulated to represent Iams ${ }^{\bullet}$ Proactive Adult Original wth Chicken Dry Cat Food, which is a commercially available diet that is nutritionally complete and balanced (17.3\% fat, $35.8 \%$ protein, $35.7 \%$ carbohydrate, $4041 \mathrm{kcal} / \mathrm{kg}$ dry matter). The MH diet was made by incorporating a water-soluble extract of whole- fruit avocado ( $\mathrm{MH}$ source; Kemin Industries, Des Moines, IA) into the CON diet to deliver a MH dose of approximately $815 \mathrm{mg} / \mathrm{kg}$ diet (as described by ref. [1]). As no studies have fed MH to cats before, the targeted dietary dose selected was similar to that given to canines by McKnight et al. [1] to allow for comparison of plasma MH kinetics between species.

*Corresponding author: Shoveller A, Centre for Nutrition Modeling, Department of Animal Biosciences, University of Guelph, Canada, Tel: (519) 824-4120, extn. 53140; E-mail: ashovell@uoguelph.ca

Received August 31, 2017; Accepted September 12, 2017; Published September 20, 2017

Citation: Shoveller AK, McKnight LL, Davenport GM (2017) Plasma Mannoheptulose Kinetics in Adult Domestic Short-Haired Felines. J Formul Sci Bioavailab 1: 114

Copyright: (c) 2017 Shoveller AK, et al. This is an open-access article distributed under the terms of the Creative Commons Attribution License, which permits unrestricted use, distribution, and reproduction in any medium, provided the original author and source are credited. 
Each animal was fed to their maintenance energy requirement, based on historical records of the individual dietary energy required to maintain body weight ( $\sim 63 \mathrm{kcal} / \mathrm{kg}$ BW/d). Diets were present in dry, kibble form, and felines were fed individually once daily at 07:00 and allowed one hour to eat. All remaining food was collected and weighed to account for total food refusal. Body weight was measured weekly.

\section{Meal challenge}

Animals were fasted overnight and anaesthetized using butorphanol $(0.25 \mathrm{mg} / \mathrm{kg})$ and dexmedetomidine $(0.0125 \mathrm{mg} / \mathrm{kg})$. An 18 gauge SurFlash ${ }^{\circledR}$ polyurethane catheter (Terumo Medical Products, Butler, Ohio) was aseptically inserted into the jugular vein and the cat's neck was covered with stockinet to prevent the animal from coming in contact with the catheter. At the end of the procedure, each cat was administered atipamezole $\left(0.125 \mathrm{mg} / \mathrm{kg}\right.$, Antisedan ${ }^{\oplus}$, Pfizer) as a sedative reversal and placed in a heated cage to recover.

Six hours after catheter placement one fasting blood sample was collected after which each cat was offered their full daily ration of test diet (CON or $\mathrm{MH})$. Cats were fed individually and given $1 \mathrm{~h}$ to consume their test meal. Timing for blood sampling was initated once

\begin{tabular}{|c|c|c|c|c|}
\hline Animal & BW $\mathbf{( k g )}$ & Time $^{\mathbf{1}}$ & Food Intake (g) & MH Intake (mg) \\
\hline 1 & 4.11 & 60 & 42 & 31 \\
\hline 2 & 4.05 & 60 & 52 & 38 \\
\hline 3 & 4.57 & $<20$ & 63 & 46 \\
\hline 4 & 3.97 & $<20$ & 52 & 38 \\
\hline 5 & 3.91 & $<20$ & 44 & 32 \\
\hline 6 & 4.03 & $<20$ & 13 & 10 \\
\hline 7 & 4.33 & $<20$ & 59 & 43 \\
\hline 8 & 4.27 & $<20$ & 39 & 28 \\
\hline Mean \pm SD & $4.15 \pm 0.22$ &. & $41.2 \pm 13.3$ & $37.1 \pm 12.6$ \\
\hline
\end{tabular}

Table 1: Body weight, food and mannoheptulose consumption $(\mathrm{mg})$ in adult domestic short hair cats fed a single meal of a $\mathrm{MH}$ containing diet. Time allotted in minutes for individual felines to consume test diet. the animal consumed approximately half of his or her test meal (less than $15 \mathrm{~min}$ for all cats). Blood samples $(2 \mathrm{~mL})$ were collected from the catheter using $1 \mathrm{~mL}$ syringes, every $2 \mathrm{~h}$ up to $24 \mathrm{~h}$ post-feeding. Blood was centrifuged for $8 \mathrm{~min}$ at $3,000 \times \mathrm{g}$ at $7^{\circ} \mathrm{C}$ and the serum was stored separately at $-80^{\circ} \mathrm{C}$ for subsequent analysis of $\mathrm{MH}$. Plasma $\mathrm{MH}$ was determined by HPLC tandem mass spectrometry as described by McKnight et al. [1].

\section{Calculations}

Plasma MH concentrations at any time point $(\mathrm{t})$ were described by an apparent zero-order absorption phase with first order elimination kinetics. Graphpad Prism version 6.04 (Graphpad Software, La Jolla California, USA, www.graphpad.com) was used to estimate area under the curve (AUC) using linear trapezoid rule and Microsoft Excel (2007) to determine: first order elimination rate constant (ke), elimination half-life (t1/2 in hours), apparent zero order absorption rate constant ( $\mathrm{K} 0$ in $\mu \mathrm{g} / \mathrm{kg} / \mathrm{hr}$ ), and turnover time (h). Concentration at steady state (Css) was estimated from the visual inspection and where the change in slope was $<10 \%$. All data are presented as mean and SEM (Table 2).

\section{Results and Discussion}

The primary aim of this study was to determine the appearance of ingested $\mathrm{MH}$ into the peripheral circulation of adult domestic short hair cats fed a $\mathrm{MH}$ containing diet. $\mathrm{MH}$ appeared into circulation within $2 \mathrm{~h}$, remained at an apparent steady state for $11 \mathrm{hr}$ post meal feeding, and disappeared within $24 \mathrm{~h}$ of ingestion (Figure 1). $\mathrm{MH}$ rate of appearance was described by a zero order rate of appearance of 0.52 $\pm 0.13 \mathrm{ng} / \mathrm{kg} / \mathrm{hr}$ and first order rate of disappearance $\left(0.38 \pm 0.04 \mathrm{~h}^{-1}\right)$ resulting in a half-life of $1.86 \pm 0.20(\mathrm{~h})$ and turnover time of $2.68 \pm 0.29$ (h). These findings confirm that $\mathrm{MH}$ is at least partially absorbed intact and biologically available to the animal.

In order to adequately describe the appearance and disappearance of $\mathrm{MH}$ (or any substrate) repeated blood sampling at multiple time

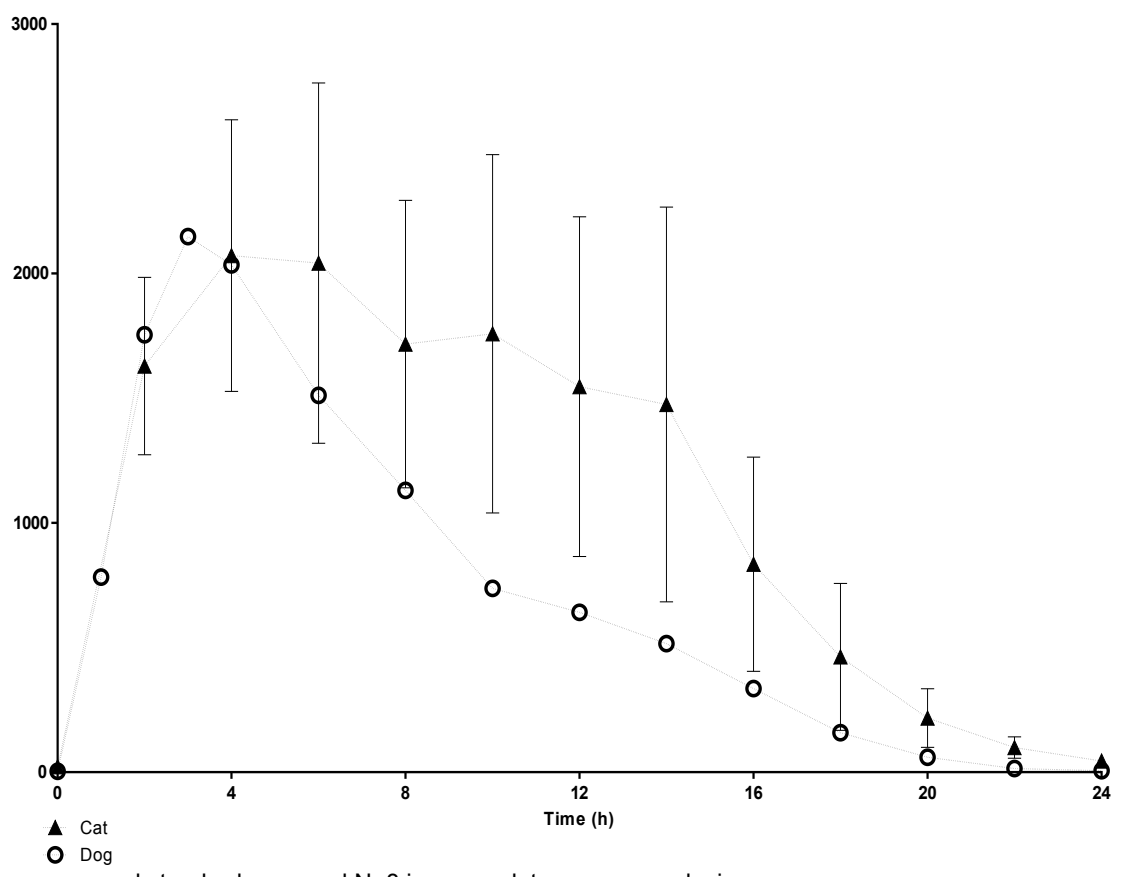

${ }^{1}$ Data are presented as means and standard error and $\mathrm{N}=8$ in a complete cross-over design.

Figure 1: Plasma mannoheptulose $(\mathrm{ng} / \mathrm{mL})$ concentrations in adult domestic short hair felines fed a mannoheptulose containing meal at time zero'. For comparison, post-prandial plasma mannoheptulose concentrations in adult Beagles are also presented (adapted from ref. [1]). 
Citation: Shoveller AK, McKnight LL, Davenport GM (2017) Plasma Mannoheptulose Kinetics in Adult Domestic Short-Haired Felines. J Formul Sci Bioavailab 1: 114.

\begin{tabular}{|l|c|}
\hline \multicolumn{1}{|c|}{ Parameter } & Mean Estimate (SEM) \\
\hline $\mathrm{C}_{\mathrm{ss}, \mathrm{av}}(\mathrm{ug} / \mathrm{mL})$ & $1.79 \pm 0.48$ \\
\hline $\mathrm{AUC}(\mu \mathrm{g} \cdot \mathrm{hr} / \mathrm{mL})$ & $26.10 \pm 8.11$ \\
\hline $\mathrm{K}_{\mathrm{o}}(\mathrm{ng} / \mathrm{kg} / \mathrm{hr})$ & $0.52 \pm 0.13$ \\
\hline $\mathrm{K}_{\mathrm{E}}\left(\mathrm{h}^{-1}\right)$ & $0.38 \pm 0.04$ \\
\hline $\mathrm{T}_{1 / 2}(\mathrm{~h})$ & $1.86 \pm 0.20$ \\
\hline Turnover time $(\mathrm{h})$ & $2.68 \pm 0.29$ \\
\hline
\end{tabular}

Table 2: Post-prandial $(24 \mathrm{~h})$ plasma mannoheptulose kinetics in adult domestic short hair felines fed a mannoheptulose containing diet $(8 \mathrm{mg} / \mathrm{kg}$ as fed). Css: Concentration at Steady State; AUC: Area Under Curve; $\mathrm{K}_{0}$ : Absorption Constant; $\mathrm{K}_{\mathrm{E}}$ : Elimination Constant; $\mathrm{T}_{1 / 2}$ : Half Life.

points is required. In the cat, this type of methodology is not without challenge. For example, the insertion of venous catheters was necessary and required the use of sedation and general anesthesia. Despite successful catheter insertion, catheters became blocked in two of the cats and these data were not included in the final analysis. As the cat is small in body size (blood volume) relative to the dog, fewer blood samples were taken in the present study in comparison to McKnight et al. [1]. As a result, the appearance and disappearance of $\mathrm{MH}$ into peripheral circulation was not adequately captured and may involve more than a single pool for both appearance and disappearance kinetics. Another challenge in determining the plasma kinetics of a dietary substrate in cats is the cats' feeding behavior. Food and $\mathrm{MH}$ intakes are given in Table 1. Six out of the eight felines consumed their test meal within 15-20 min, whereas, two cats required $1 \mathrm{~h}$ to consume their entire meal (Table 1) and still did not consume everything supplied to them. Unlike the dog who typically consumes a single discrete meal, cats consume multiple small meals. Therefore describing the initial appearance of $\mathrm{MH}$ was not possible.

In comparison to the dog [1], plasma $\mathrm{MH}$ concentrations in the cat remained elevated for several hours post-ingestion. In contrast, elimination kinetics followed first order processes, meaning the $\mathrm{MH}$ rate of elimination was dependent upon its plasma concentration. This finding is in agreement with McKnight et al. [1] who noted first order elimination kinetics in Beagles fed a similar dietary dose of $\mathrm{MH}$. In comparison to canines, felines experienced a faster rate of elimination than canines ( $\mathrm{MH}$ half-life in dogs $3.7 \mathrm{~h}$ vs. $2.5 \mathrm{~h}$ for cats). Differences in plasma MH kinetics may have been attributed to several physiological differences between species, specifically differences in gastrointestinal physiology, gastric emptying rate, and the digestion, absorption and metabolism of dietary carbohydrates. In the dietary matrix, $\mathrm{MH}$ is not bound to any other compounds, therefore, differences in digestive physiology between species were not believed to impact the absorption and digestibility of $\mathrm{MH}$ from the gastrointestinal tract [7]. It is more likely the route by which $\mathrm{MH}$ is absorbed affects the rate of $\mathrm{MH}$ appearance in peripheral circulation. Indeed, in contrast to omnivorous species, hepatic glucose disposal in the cat is regulated by hexokinase which has a high affinity for glucose thereby limiting the rate of appearance of $\mathrm{MH}$ in peripheral circulation [8]. This idiosyncrasy in hepatic glucose regulation may, in part, explain the observed sustained plateau in plasma $\mathrm{MH}$ concentrations.

In conclusion, $\mathrm{MH}$ is absorbed by the gastrointestinal tract of the cat and appears in peripheral circulation within $2 \mathrm{~h}$ of ingestion. Plasma MH concentrations are sustained in the cat for considerably longer than observed in the dog. The biological significance, if any, of sustained $\mathrm{MH}$ concentrations is presently unclear and would warrant further study. These results may however suggest that cats need lower doses or less frequent dosing for $\mathrm{MH}$ as compared to dogs. Furthermore, more work to investigate the potential benefits, such as the influence of $\mathrm{MH}$ on circulating glucose and insulin (and C peptide) concentrations, would be logical progression of this work.

\section{Acknowledgements}

Zhang $\mathrm{J}$ and Flickinger EA helped to the experimental design and A Gerwin, $\mathrm{G}$ Ruschman and $\mathrm{G}$ Balan provided direction on the interpretation of mannoheptulose kinetic results.

\section{Funding}

This study was funded by The lams Company, Procter and Gamble Pet Care.

\section{Conflict of Interest}

Shoveller AK and Davenport GM were employees of The lams Company at the time this work was completed.

\section{References}

1. McKnight LL, Flickinger EA, France J, Davenport GM, Shoveller AK (2014) Mannoheptulose has differential effects on fasting and post-prandial energy expenditure and respiratory quotient in adult Beagle dogs fed diets of different macronutrient contents. J Nutr Sci 3: e17.

2. McKnight LL, Flickinger EA, Davenport GM, France J, Shoveller AK (2015) Dietary mannoheptulose has differential effects on fasting and post-prandial glucose oxidation in Labrador Retrievers. J Appl Anim Res 43: 357-365.

3. McKnight LL, Erye R, Gooding M, Davenport GM, Shoveller AK (2015) Dietary mannoheptulose increases fasting serum glucagon like peptide-1 and postprandial serum ghrelin concentrations in adult Beagle dogs. Animals 5: 442-454.

4. McKnight LL, Root-McCaig J, Wright D, Davenport GM, France J, et al. (2015) Dietary mannoheptulose does not significantly alter daily energy expenditure in adult Labrador Retrievers. PLoS One 10: e0143324.

5. Crane RK, Sols A (1954) The non-competitive inhibition of brain hexokinase by glucose-6-phosphate and related compounds. J Biol Chem 10: 597-606.

6. Coore HG, Randle PJ (1964) Inhibition of glucose phosphorylation by mannoheptulose. Biochem J 91: 56-59.

7. Ballard FJ (1965) Glucose utilization in the mammalian liver. Comp Biochem Physiol 14: 437-443.

8. Tanaka A, Inoue A, Takeguchi A, Washizu T, Bonkobara M, et al. (2005) Comparison of expression of glucokinase gene and activities of enzymes related to glucose metabolism in livers between dog and cat. Vet Res Comm 29: 477-485. 